\title{
The influence of emotional intelligence and resilience on work engagement amongst nurses in public hospitals
}

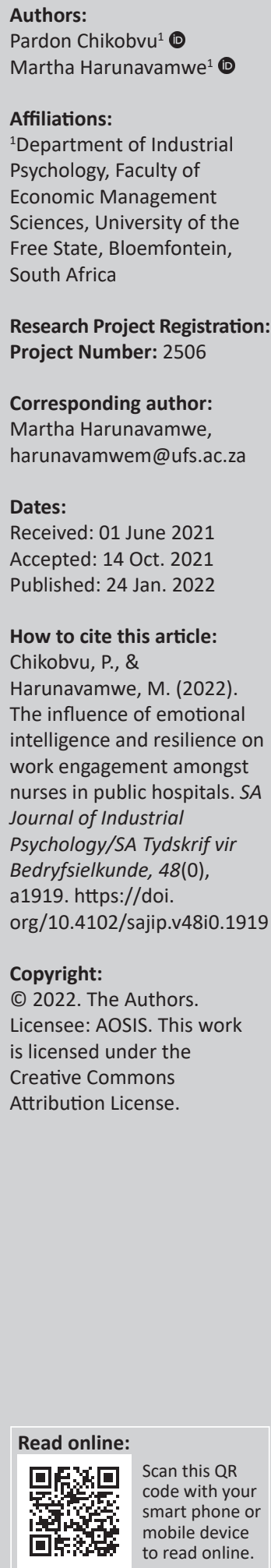

Orientation: It has become vital for hospitals to create supportive and conducive working environments. With the reported adverse working conditions in public hospitals, it would be prudent to consider the stimulating factors of work engagement. This research suggests that personal resources such as resilience and emotional intelligence may cushion individuals from being disengaged by enabling them to manage job demands.

Research purpose: The study aimed to determine the extent to which a combination of positive aspects and resources of emotional intelligence and resilience may influence work engagement.

Motivation for the study: The study was inspired by Demerouti and Bakker who in 2011 signalled that employees become susceptible to health impairments when job and personal resources are likely to be limited. Expanding employee personal resources may thus effectively influence work engagement.

Research approach, design and method: The study employed a cross-sectional quantitative survey by means of self-administered questionnaires. The sample consisted of 252 nurses from the Mangaung Metropolitan Municipality, South Africa. Data were analysed using the SmartPLS programme.

Main findings: Emotional intelligence influences work engagement through resilience. The strong direct pathway between emotional intelligence and work engagement was noteworthy.

Practical/managerial implication: Managers may focus their attention on developing aspects of emotional intelligence and enhance resilience as a way of improving work engagement.

Contribution/value-add: The findings add literature to the body of knowledge focusing on expanding personal resource as a way to enhance work engagement amongst nurses in public hospitals.

Keywords: nurses; work engagement; emotional intelligence; resilience; personal resources; perseverance; self-reliance; self-regulation; vigour; absorption.

\section{Introduction}

The work engagement of nurses in the public hospitals has become more critical than ever due to the pressure caused by the coronavirus disease, 2019 (COVID-19) pandemic (Giménez-Espert, Prado-Gascó, \& Soto-Rubio, 2020). As an integral part of the frontline personnel, the quality of the healthcare they provide depend on their well-being, their performance and their levels of engagement (Giménez-Espert et al., 2020). However, as a result of the pressure of having to perform their duties under dire circumstances, nurses in South Africa experience work-related stress that may lead to disruptions in both psychological and physical health, which, in turn, may negatively affect their engagement at work (Khamisa, Peltzer, Ilic, \& Oldenburg, 2015). Nurse shortage, work overload, uncompetitive remuneration, inadequate management, unsatisfactory working environment and work-place violence characterise the South African healthcare fraternity (Janse van Rensburg et al., 2016). These aspects leave employees with feelings of fear, hostility and anxiety, which can lead to stress and mental strain that may threaten employees' ability to be engaged (Boafo, 2018; Kennedy \& Julie, 2013; Terblanche \& Borcherds, 2018).

Maphumulo and Bhengu (2018) indicated that nurses experience higher degrees of work-related strains because of the interpersonal and personal circumstances and risks posed by contact with patients. Rispel (2015) posed that exposure to the suffering of human beings, death, grief and interpersonal conflict leave the nurses emotionally drained. Resultantly, they experience the 
emotional labour of managing their own and others' negative emotions. Hart, Brannan and Chesnay (2014) added that nurses also suffer from psychological feelings of emptiness because of frustrations in the workplace. They are left feeling depressed and unable to manage their emotions, which results in them having diminished inner balance (Bjarnadotti, 2011). Maphumulo and Bhengu (2018), concurring with Hart et al. (2014), concluded that, faced with such dilemmas, leaders and human resources practitioners need to revise the way they consider nurses' engagement in order to improve efficiency and promote good healthcare.

Work engagement is identified as a key factor in achieving corporate success (Shuck \& Herd, 2012). The South African Department of Health (as cited in Janse van Rensburg et al., 2016) argued that promoting engagement empowers nurses, whilst empowered nurses provide better patient care. In the same perspective Bonner (2016) argued that engagement amongst nurses is associated with reduced patient death rates in hospitals and business profitability and success. Although work engagement is crucial for organisational success, Shuck and Herd (2012) argued that engagement levels amongst employees have steadily dropped. Scholars (e.g. Banhwa, Chipunza, \& Chamisa, 2014; Bjarnadotti, 2011; Dewing \& McCormack, 2015; Freeney \& Fellenz, 2013; Simons \& Buitendach, 2013) have suggested that the drop in engagement levels might be because of ineffective models or mechanisms employed to engage employees.

In the light of improving efficiency and engagement amongst healthcare employees, Dewing and McCormack (2015) proposed and advised organisations to value human social capital management, focusing on positive human strengths and personal resources. Prins, Van Niekerk and Weyers (2018) and Albrecht (2010), pointed out that personal resources can alleviate the negative effects of external stimuli on work engagement, because they enable employees to have positive attitude at work. In the same view, Bakker and Demerouti (2014) observed that personal resources help individuals appraise themselves, which then enables them to control and adapt well to their environment. Xanthopulou, Bakker, Demerouti and Schaufeli (2007) added that personal resources also help individuals to create more aspects that facilitate goal attainment. As a result, they engage in goal confrontation, consequently leading to work engagement. The most common personal resources are: resilience, self-efficacy, self-esteem, emotional intelligence, optimism and hope (Bjarnadotti, 2011; Simons \& Buitendach, 2013). Garrosa, Moreno-Jiménez, RodríguezMuñoz and Rodríguez-Carvajal (2011) argued that personal resources, such as emotional intelligence and resilience, have been widely studied, but with less emphasis in relation to engagement. It is thus important to investigate the influence of resilience and emotional intelligence on work engagement amongst nurses. This article presents a theoretical model that integrates emotional intelligence, resilience and work engagement.

\section{Research purpose and objectives}

The study intended to determine whether emotional intelligence and resilience influence work engagement amongst nurses in public hospitals. The objectives were to:

- determine the influence of emotional intelligence and resilience on work engagement

- establish the influence of emotional intelligence on work engagement

- determine the mediating role of resilience in the relationship between emotional intelligence and work engagement.

\section{Literature review}

Work engagement is a unique phenomenon that has roused interest of researchers and practitioners because of its positive impact on competitive advantage and performance (Bailey et al., 2017). The concept has its roots in burnout literature and it emerged as an attempt to shift the focus from an employee's ill-being to an employee's well-being (Albrecht, 2010). Schaufeli, Salanova, González-Romá and Bakker (2002) defined work engagement as a positive, fulfilling, workrelated state of mind characterised by full concentration in one's work and having high levels of energy and enthusiasm whilst working. It is characterised by vigour, dedication and absorption.

Work engagement has been linked with benefits for both individuals and organisations, it increases employee motivation and commitment (Bonner, 2016). Bailey et al. (2017) reported that work engagement promotes occupational health and consequently brings financial success to organisations. Jacobs, Renard and Snelgar (2014) reported that work engagement is linked to lower absenteeism, safety at work and employee empowerment. Moreover, Bakker and Leiter (2010) argued that work engagement is an important strategy for organisations as it may contribute to the physical, emotional and mental well-being of employees. Correspondingly, Van der Walt (2018) pointed out that engaged employees display positive attitudes towards their work, commit emotionally to their work and are likely to be engrossed in their work. However, although engaged employees drive production and exhibit safety behaviour (Takawira, Coetzee \& Schreuder, 2014), engagement levels globally are not very high (Naidoo, Abarantyne, \& Rugimbana, 2019). Specifically, Naidoo et al. (2019) highlighted that $64 \%$ of employees globally are not engaged. This indicates that the problem of engaging employees still exists despite the importance of engagement in the 21st century. It is therefore time to implement new ways of improving work engagement. Demerouti and Bakker (2011) forwarded that expanding personal resources may be effective in boosting work engagement.

As indicated earlier, several personal resources have been recognised and empirically examined as antecedents of work engagement (Bjarnadotti, 2011; Garrosa et al., 2011; Simons \& Buitendach, 2013; Xanthopulou et al., 2007). Considering that 
nurses are faced with a demand for efficiency and improved healthcare quality, they need to be able to deal effectively with the demands and stresses of their jobs (Jacobs et al., 2014). Based on the job demands-resources model, personal resources may act as a buffer against job demands and in turn improve work engagement (Bakker \& Demerouti, 2014). Through personal resources, peoplecan makestrong positive evaluations of themselves and, in turn, create a more resourceful work environment. Personal resources are defined by Bakker and Demerouti (2014) as forms of resources that are generally linked with resiliency, self-efficacy and self-esteem. These resources assist individuals in controlling and adapting to their work environment successfully (Bakker \& Demerouti, 2014). As highlighted earlier the most common personal resources include resilience, self-efficacy, self-esteem, emotional intelligence, optimism, hope and organisational-based selfesteem (Bjarnadotti, 2011; Simons \& Buitendach, 2013). The purpose of this study is to examine whether the expansion of personal resources of emotional intelligence and resilience could be the mechanisms to boost work engagement levels.

\section{Emotional intelligence and work engagement}

Emotional intelligence is viewed as the ability to recognise and regulate emotions in oneself and in others to achieve successful work performance (Goleman, 1995). The concept consists of five dimensions, namely self-awareness, motivation, selfregulation social skills and empathy (Toyama \& Mauno, 2017). Individuals high in emotional intelligence can regulate emotions are sociable and encourage positive attitude in the workplace (Prins et al., 2018). Experiencing a positive mood encourages individuals to develop and maintain positive attitude towards their jobs. Hence, employees who possess higher emotional intelligence may effortlessly display positive, fulfilling, work-related mood states, which constitute work engagement (Extremera, Mérida-López, Sánchez-Álvarez, \& Quintana-Orts, 2018). Moreover, Bartlett (2015) pointed out that emotional intelligence enables individuals to work more effectively with others and to be more engaged cognitively with their work activities.

Hypothesis 1: Emotional intelligence has a positive influence on work engagement.

\section{Resilience and work engagement}

Resilience is defined as an individual's adaptive capacity; the concept is characterised by existential aloneness, perseverance, self-reliance, meaningfulness and equanimity (Wagnild \& Young, 1993). These characteristics are viewed as personal resources that act to mitigate the negative effect of job demands. Resilience positively influence work-related outcomes such as work engagement (Bhootrani \& Junejo, 2016; Geldenhuys, Łaba, \& Venter, 2014; Meintjes \& Hofmeyr, 2018). Othman and Nasurdin (2011) observed that resilient individuals tend to be successful in dealing with workplace adversity. In turn, they are able to deal with workplace adversities, produce persistent and favourable work attitudes leading to engagement. However, studies (e.g. Bonner, 2016; Meintjies \& Hofmeyr, 2018) pointed out that, although the relation between resilience and engagement is supported empirically, the research is limited; further research should extend the focus on resilience and work engagement in several work settings such as the nursing industry.

Hypothesis 2: Resilience has a direct influence on work engagement.

\section{Relationship between emotional intelligence, resilience and work engagement}

Pérez-Fuentes, Molero Jurado, Gázquez Linares and Oropesa Ruiz (2018) indicated that emotional intelligence and resilience are important resources to enhance work engagement. Magnano, Craparo and Paolillo (2016) argued that resilience strengthens the positive effect of emotional intelligence on work engagement. Schneider, Lyons and Khazan (2013) argued that managing emotions in self and others lowers threat appraisals and lessens negative effects, which then fuel coping in the form of resilience. Resilience is then argued to motivate endurance in the face of obstacles and promote positive states, such as self-reliance, meaningfulness, confidence and optimism, as well as challenging orientation (Meintjes \& Hofmeyr, 2018). These resilient attitudes and behaviours are suggested to significantly influence individuals' levels of engagement.

From the foregoing discussion, emotional intelligence is the point of entry on the proposed relationship (between emotional intelligence, resilience and work engagement). Magnano et al. (2016) stated that emotional intelligence enables individuals to accurately assess their environment, express empathy, prioritise problems and organise thoughts, which consequently create positive active coping skills such as resilience resources. These resilience resources, in turn, enable the build-up of an energy reservoir to fuel vigour, dedication and absorption - all positive states that characterise engagement (Brennan, 2017; Meintjes \& Hofmeyr, 2018).

Hypothesis 3: Resilience mediates the relationship between emotional intelligence and work engagement.

\section{Research design Research approach}

The study used a quantitative approach, which is rooted in the positivist paradigm. As the study involved validation, hypothesis testing and describing associations between the predictors (resilience and emotional intelligence) and the outcome variable (work engagement), the quantitative approach was most appropriate. Specifically, the study employed a crosssectional survey as the researcher wanted to get an overall picture of a phenomena at a particular point in time.

\section{Research method Research participants}

The study population was nurses in the Manguang Metropolitan Municipality's district public hospitals. Nurses were selected from three hospitals in Mangaung Metro, namely 
Pelonomi, Botshabelo and National hospital with a total population of 938 nurses. Nurses who voluntarily accepted to participate in the study completed the questionnaires, thus the study employed a non-probability convenience sampling procedure. Considering the busy schedule of these nurses, voluntary participation was deemed suitable. The researcher approached the professional nurse in charge of the specific wards and asked for permission to distribute the questionnaires during their meetings amongst the nursing staff. Nurses who were available and willing to take part in the study including the professional nurses, enrolled nurses, staff nurses and assistant nurses completed the questionnaires. Thus, the participants consisted of professional nurses, assistant nurses, enrolled nurses and staff nurses.

The total number of questionnaires distributed were 335 out of which only 282 were returned; of the 282 only 252 were eligible to be captured. Thus, the study had a response rate of $75.2 \%$.

\section{Measuring instrument}

The data gathering tool had four sections. The first section (Section A) was a biographical questionnaire where respondents answered six items relating to age, category, area of speciality, length of service, highest qualification received and gender. The other sections consisted of preestablished scales, namely the Utrecht Work Engagement Scale (UWES) (Section B), Rahim Emotional Quotient Index (REQI) (Rahim et al., 2002) (Section C) and the Wagnild and Young Resilience Scale (Section D).

The 17 item, UWES by Schaufeli and Bakker (2004) was used to measure work engagement. Responses were scored on a 6 -point Likert scale ranging from ' 0 ' never to ' 6 ' always. Schaufeli and Bakker (2004) reported an acceptable reliability coefficient for the scale $(\alpha=0.86)$. In a South African study, Simon and Buitendach (2013) observed the following alpha coefficients for the three subcomponents: vigour $(\alpha=0.90)$, dedication $(\alpha=0.86)$ and absorption $(\alpha=0.85)$. Simon and Buitendach (2013) found no evidence of item-bias on the measure in the various race groups. This study obtained acceptable internal consistencies for the subscales vigour $(\alpha=$ $0.776)$, dedication $(\alpha=0.840)$ and absorption $(\alpha=0.798)$.

The REQI (Rahim et al., 2002) was used to assess the nurse's emotional intelligence. The instrument comprised 22 items consisting of five factors, namely self-awareness, social skills, motivation, self-regulation and empathy. The tool uses a 7 -point Likert scale $(1=$ strongly disagree to $7=$ strongly agree). In a South African sample, Nel, Du Plessis and Bosman (2015) reported an internal consistency reliability coefficient of the five subscales ranging between 0.844 and 0.994. Nel et al. (2015) commented that the instrument is standardised and valid for the South African population. This study obtained the following reliability scores for the five subscales: self-awareness $(\alpha=0.810)$, self-regulation ( $\alpha=0.763)$, empathy $(\alpha=0.733)$, motivation $(\alpha=0.820)$ and social skills $(\alpha=0.705)$ (see Table 1$)$.
TABLE 1: Reliability estimates for the work engagement, emotional intelligence and resilience scale.

\begin{tabular}{lcc}
\hline Scale & Number of items & Cronbach's alpha \\
\hline Vigour & 6 & 0.776 \\
Dedication & 5 & 0.840 \\
Absorption & 6 & 0.798 \\
Work engagement (Total) & 17 & 0.916 \\
Self-awareness & 4 & 0.810 \\
Self-regulation & 5 & 0.763 \\
Empathy & 4 & 0.733 \\
Motivation & 5 & 0.820 \\
Social skills & 4 & 0.705 \\
Emotional intelligence (Total) & $\mathbf{2 2}$ & $\mathbf{0 . 9 3 4}$ \\
Resilience & $\mathbf{1 4}$ & $\mathbf{0 . 8 8 9}$ \\
\hline
\end{tabular}

Note: The bold values indicate the reliability scores of the composite scales.

The resilience scale RS-14 (Wagnild \& Young, 2009) was used to assess nurses' resilience. The scale comprises 14 items making up five components of the scale, namely perseverance, equanimity, self-reliance, existential aloneness and meaningfulness. All items were scored on a 7-point Likert scale that ranged from $1=$ disagree to $7=$ agree. Koen, Van Eeden and Wissing (2011), in a South African sample, reported acceptable reliability scores for the scale with coefficient alpha of 0.80 and test-retest coefficients of 0.60 0.98 . Koen et al. (2011) commented that the construct validity of the measuring instrument indicate that the scale is valid and could be used to assess resilience amongst nurses in South Africa. In this study, the instrument achieved an acceptable internal consistency score $(\alpha=0.889)$.

\section{Data analysis}

Tools such as the Statistical Package for the Social Sciences (SPSS) version 24, Lisrel 10.0 and SmartPLS were used to analyse the collected data. Descriptive and inferential statistics were used to summarise data and test research hypotheses. Cronbach's alpha was used to assess the internal consistency reliability of the measuring instruments. A confirmatory factor analysis (CFA) through assessment of the goodness of fit statistics (comparative fit index [CFI], root mean square error of approximation [RMSEA], standardised root mean square residual [SRMR]) was used to determine the psychometric properties of the measuring instruments. Variance-based structural equation modelling (SEM) SmartPLS was used to test the model with direct and indirect links between emotional intelligence, resilience and work engagement.

The model was tested following a two-stage process, encompassing (1) the assessment of the measurement model, then (2) the assessment of the structural model.

Firstly, the outer model (i.e. measurement model) was evaluated in terms of internal consistency (composite reliability), convergent (average variance extracted [AVE] scores) and discriminant validity (heterotrait-monotrait [HTMT] values). The purpose of the outer model is to determine whether the measurements used to operationalise each of the latent variables are reliable and valid. The quality 
criteria associated with an acceptable outer model are: (1) AVE of 0.5 and higher, (2) composite reliability estimates of 0.7 and higher and (3) HTMT ratio of correlations cut-off score of 0.90 (Hair, Risher, Sarstedt, \& Ringle, 2019). Secondly, the structural model was evaluated using the following guidelines: (1) the size of the path coefficients (beta values), (2) significance of the path coefficients and (3) the amount of variance explained in the dependent variable by the proposed model.

\section{Ethical considerations}

Ethical clearance to conduct this study was obtained from the University of the Free State Health Sciences Research Ethics Committee (reference number: UFS-HSD2019/0077/2506). After permission was granted by the Free State Department of Health, questionnaires were distributed to the nurses in the public hospitals. Voluntary participation, anonymity and confidentiality were guaranteed.

\section{Results \\ Demographic information}

Nurses between the ages of 41 and 50 years constituted the largest group within the sample (31.3\%) and the majority of the nurses surveyed were females (80.2\%). Most of the respondents were from the medical nursing department, constituting $28.6 \%$ of the sample. The highest level of academic study achieved by the nurses who participated was an advanced diploma (39.7\%). Only a few nursing employees had undergraduate $(5.6 \%)$ and postgraduate degree qualifications (15.1\%). Most participants $(23.8 \%)$ had been in the organisation for 6-10 years. In terms of nursing category, majority of the participants were enrolled nurses who made up $39.7 \%$ of the sample, followed by assistant nurses making up $29.6 \%$ and the least were the professional nurses, constituting $20.7 \%$ of the sample. The qualifications held by the different categories of nurses together with the nature of work the nurses perform were observed.

\section{Validity and reliability of the questionnaire}

Confirmatory factor analysis through the goodness of fit statistics confirmed the distinctive validity of emotional intelligence, resilience and work engagement. Reliability of the measuring instruments was assessed using Cronbach's alpha coefficient and composite reliability.

The Cronbach's alpha for the work engagement dimensions (measured by the UWES-17) may be regarded as good (vigour $=0.776$, dedication $=0.840$, absorption $=0.798)$. The internal consistency for emotional intelligence, consisting of five dimensions, is good, ranging from 0.820 for motivation to 0.705 for social awareness. Resilience observed a reliability score of $\alpha=0.899$, which is comparable to that of Wagnild and Collins (2009) ( $\alpha=0.91)$.

On examining Table 2, it is evident that, for emotional intelligence, the following fit indices were reported: CFI
(0.966), RMSEA (0.134) and SRMR (0.0863). The CFI value for this study is comparable to that of Nel et al. (2015) who reported a slightly lower, but fitting model for the CFI (0.950) in a South African sample. Nel et al. (2015) further reported a value of 0.055 for the RSMEA and this study observed a value of 0.134, which is higher and interpreted as a poor fit, according to Hair et al. (2019). This study observed an SRMR value of 0.0863 , which is higher than the 0.035 observed by $\mathrm{Nel}$ et al. (2015). However the higher value observed is acceptable when using a cut-off score of 0.10 , as suggested by Kline (2011).

For the goodness of fit results on work engagement, the following results are reported: CFI $=0.930, \mathrm{SRMR}=0.0718$.

Goodness of fit indexes on resilience was reported as follows: $\mathrm{CFI}=0.984, \mathrm{RMSEA}=0.190$ and $\mathrm{SRMR}=0.0919$. The results of the CFI are comparable to those of previous studies, for example, Aiena, Baczwaski, Schulenberg and Buchanan (2015), who reported an acceptable but lower CFI than that of this study $(C F I=0.92)$. Damasio, Borsa and Da Silva (2011) reported a value of 0.056 for the RMSEA and this study reported a RMSEA $=0.190$, which is indicative of poor fit. For the SRMR, Damasio et al. (2011) observed a value of 0.042 and the present study reported a higher value of 0.0929 , which is a value larger than 0.08 , but regarded as an acceptable fit (Kline, 2011). The model was well fitting, given that two of the three fit statistics (CFI and SRMR) were acceptable.

Table 3 shows that the composite reliability scores for all three variables were excellent $(>0.9)$. Thus, the three variables observed satisfactory composite reliability scores, namely emotional intelligence (0.926), resilience (0.912) and work engagement (0.925). The convergent validity of the measuring instruments in the measurement model assessed through the AVE score was also good. The AVE scores were above 0.5 (emotional intelligence $=0.715$, work engagement $=0.805$, resilience $=0.675)$.

Table 4 shows the results for discriminant validity. The following HTMT values were recorded for the constructs: resilience and work engagement (0.516), resilience and emotional intelligence (0.705) and emotional intelligence and

TABLE 2: Goodness of fit statistics.

\begin{tabular}{lcccccc}
\hline Variable & S-B $\chi \mathbf{2}$ & df & CFI & RMSEA & SRMR & $\boldsymbol{p}$ \\
\hline WE & 273.765 & 116 & 0.930 & $0.132(0.121 ; 0.143)$ & 0.0718 & 0.0000 \\
RES & 100.811 & 67 & 0.984 & $0.190(0.176 ; 0.204)$ & 0.0919 & 0.0048 \\
EI & 312.788 & 199 & 0.966 & $0.134(0.126 ; 0.143)$ & 0.0863 & 0.0000 \\
\hline
\end{tabular}

$\mathrm{EI}$, emotional intelligence; $\mathrm{RES}$, resilience; $\mathrm{WE}$, work engagement; $\mathrm{CFI}$, comparative fit index; RMSEA, root mean square error of approximation; SRMR, standardised root mean square residual.

TABLE 3: Quality criteria of the measurement or outer model.

\begin{tabular}{lcccc}
\hline Variables & Cronbach's alpha & rho_A & $\begin{array}{c}\text { Composite } \\
\text { reliability }\end{array}$ & AVE \\
\hline EMOT_INTE & 0.900 & 0.905 & 0.926 & 0.715 \\
RESILIENCE & 0.880 & 0.890 & 0.912 & 0.675 \\
W_ENGAGE & 0.879 & 0.879 & 0.925 & 0.805 \\
\hline
\end{tabular}

EMOT_INTE, emotional intelligence; W_ENGAGE, work engagement; AVE, average variance extracted. 
TABLE 4: Heterotrait-monotrait ratio.

\begin{tabular}{lccc} 
TABLE 4: & Heterotrait-monotrait ratio. & & \\
\hline Variables & EMOT_INTE & RESILIENCE & W_ENGAGE \\
\hline EMOT_INTE & - & - & - \\
RESILIENCE & 0.768 & - & - \\
W_ENGAGE & 0.575 & 0.516 & - \\
\hline
\end{tabular}

EMOT_INTE, emotional intelligence; W_ENGAGE, work engagement.

TABLE 5: Outer loadings - loading of dimensions on the latent variable.

\begin{tabular}{lccc}
\hline Dimensions & Factor loading & $\boldsymbol{t}$ & $\boldsymbol{p}$ \\
\hline Absorption: WE & 0.906 & 57.792 & $0.000^{* *}$ \\
Dedication: WE & 0.873 & 32.090 & $0.000^{* *}$ \\
Empathy: EQI & 0.839 & 36.171 & $0.000^{* *}$ \\
Equanimity: RES & 0.797 & 23.552 & $0.000^{* *}$ \\
Existential aloneness: RES & 0.777 & 20.991 & $0.000^{* *}$ \\
Meaningfulness: RES & 0.848 & 39.184 & $0.000^{* *}$ \\
Motivation: EQI & 0.844 & 34.162 & $0.000^{* *}$ \\
Perseverance: RES & 0.816 & 22.986 & $0.000^{* *}$ \\
Self-awareness: EQI & 0.854 & 48.778 & $0.000^{* *}$ \\
Self-regulation: EQI & 0.886 & 56.351 & $0.000^{* *}$ \\
Self-reliance: RE & 0.866 & 52.122 & $0.000^{* *}$ \\
Social skills: EQI & 0.872 & 45.705 & $0.000^{* *}$ \\
Vigour: WE & 0.912 & 72.104 & $0.000^{* *}$ \\
\hline
\end{tabular}

WE, work engagement; EQI, Emotional Quotient Index; RES, resilience.

$* *, p<0.001$.

TABLE 6: Partial least squares path coefficient results.

\begin{tabular}{lccccc}
\hline Variables & $\begin{array}{c}\text { Original } \\
\text { sample (O) }\end{array}$ & $\begin{array}{c}\text { Sample } \\
\text { mean (M) }\end{array}$ & $\begin{array}{c}\text { Standard } \\
\text { deviation } \\
\text { (SD) }\end{array}$ & $\begin{array}{c}\text { T statistics } \\
\text { (|O/ } \\
\text { STDEV |) }\end{array}$ & $p$ \\
\hline EMOT_INTE $\geq$ RES & 0.692 & 0.695 & 0.034 & 20.121 & $0.000^{* *}$ \\
EMOT_INTE $\geq$ W_ENG & 0.516 & 0.379 & 0.078 & 4.809 & $0.000^{* *}$ \\
RESILIENCE $\geq$ W_ENG & 0.202 & 0.200 & 0.086 & 2.349 & 0.019 \\
\hline
\end{tabular}

EMOT_INTE, Emotional intelligence; W_ENG, work engagement.

$* *, p<0.001$.

work engagement (0.575). To achieve discriminant validity, the HTMT values should be lower than 0.90 (Hair et al., 2019). This enabled the present study to proceed further to evaluate the structural model, representing the hypothetical model.

Table 5 shows the outer loadings or indicator loadings.

Table 5 indicates that all the indicators loaded significantly on their respective latent variables (factor loadings $>0.6$; $t$-values $>1.96$; $p<0.01)$.

Table 6 presents the outcomes associated with the quality criteria of the structural model. Undoubtedly all proposed paths are statistically significant, with $p<0.05$. The pathway from emotional intelligence to resilience observed the strongest path $(\beta=0.692: t$-value $=20.12$ : mean $=0.695: p=$ 0.000). Emotional intelligence to work engagement observed the second strongest path $(\beta=0.516, t$-value $=4.809$, mean $=$ $0.379, p$-value (0.000). Resilience to work engagement had the least strong statistically significant path $(\beta=0,202, t$-value $=$ 2.349 , mean $=0.702, p=0.019$ ). Table 7 shows the extent to which resilience and emotional intelligence influence work engagement. It is evident from Table 7 that the regression model explained $28.8 \%$ of the variance in work engagement, which can be interpreted as moderate. It is noteworthy that both emotional intelligence and resilience have significant
TABLE 7: R-squared represents the proportion of the variance in work engagement that is explained by resilience and work engagement.

\begin{tabular}{lcc}
\hline Variables & $\boldsymbol{R}$-square & $\boldsymbol{R}$-square adjusted \\
\hline Resilience & 0.479 & 0.477 \\
Work engagement & 0.288 & 0.282 \\
\hline
\end{tabular}

TABLE 8: Specific indirect effects.

\begin{tabular}{lccc}
\hline Variables & Indirect effect & $\boldsymbol{t}$ & $\boldsymbol{p}$ \\
\hline EMOT INTE $\geq$ RES $\geq$ W_ENGAGE & 0.145 & 1.419 & 0.157 \\
\hline
\end{tabular}

EMOT INTE, emotional intelligence; RES, resilience; W_ENGAGE, work engagement.

relationships (i.e. paths) with work engagement. These results provide support for both Hypothesis 1 and 2 .

To determine whether the relationship between emotional intelligence and work engagement is mediated by resilience, the specific indirect effects (see Table 8) should be consulted.

From Table 8, it is evident that the influence of emotional intelligence on work engagement via resilience is positive (IE $=0.145$ ) but statistically non-significant $(p=0.157)$. Although resilience positively mediated the relationship, the mediation was not statistically significant ( $t$-value 1.419 and $p$-value 0.159). Hence, the study did not support Hypothesis 3.

\section{Discussion}

The main objective of the study was to determine the influence of emotional intelligence and resilience on work engagement. It was hypothesised that the two constructs directly and indirectly influence work engagement and that emotional intelligence lays the foundation of the proposed relationship (from emotional intelligence to resilience and resilience to work engagement). This was based on the premise that emotional intelligence enables individuals to accurately assess their environment, express empathy, think according to the priority of problems and organise thoughts, which consequently increases resilience (Magnano et al., 2016). Resilience, in turn, motivates endurance in the face of obstacles and enables the build-up of an energy reservoir to fuel vigour, dedication and absorption - the positive states that characterise engagement (Kašpárkováa, Vaculíka, Prochazka, \& Schaufel, 2018; Meintjes \& Hofmeyer, 2018). As claimed by the job demands-resources model, personal resources enhance employees' positive motivational states such as work engagement. The model, as a heuristic and parsimonious framework, assumes that some resources play an important role in promoting engagement and in enhancing other resources to promote work engagement. In this context, the results of this study will be discussed in the following paragraphs.

The two independent variables (emotional intelligence and resilience) had a significant effect on work engagement. It is argued that individuals who are highly emotionally intelligent show higher concentration in their professional activities are more energetic at work and show more enthusiasm, inspiration, pride and challenge for their work (Prins et al., 2018). This implies that emotionally intelligent 
individuals experience greater vigour, dedication and absorption in the workplace (Extremera et al., 2018). Zhu, Liu, Guo, Zhao and Lou (2015) postulated that emotionally intelligent individuals, with their ability to regulate their emotions and those of others, are able to build good social relations with colleagues and supervisors, which might motivate them to work harder, be more energetic and be proud of their work.

Resilience, as a personal resource, has been argued to influence employees' ability to cope with work-related stress factors and work engagement. It is claimed that resilient individuals appraise potential stressors as less threatening and consequently they feel that it is safe to engage (Sweetman \& Luthans, 2010). Furthermore, Kašpárkováa et al. (2018) claimed that resilient individuals possess more personal resources and positive self-evaluations (e.g. internal locus of control, emotional stability, self-esteem and generalised efficacy) and the more positive self-regard a person has, the more the goal of self-concordance is achieved. Llorens, Schaufeli, Bakker and Salanova (2007) observed that individuals who have goal self-concordance have inner motivation to pursue their goals, which result in deep satisfaction, thereby promoting higher levels of engagement.

The findings demonstrate that emotional intelligence influences work engagement through resilience. The findings concur with Magnano et al. (2016) who stated that resilience strengthens the positive effect of emotional intelligence on work engagement. According to Toyama and Mauno (2017), these two types of resources seem to jointly reinforce their positive effect on outcomes such as work engagement. It is claimed that emotionally intelligent individuals have motivation and experience positive emotions from skilfully regulating their emotions. The experience of positive emotion fosters resilience as individuals are able to recover from daily stress and avoid emotional exhaustion, thereby promoting work engagement (Lestari \& Sawitri, 2017). Zhu et al. (2015) found that emotional intelligence enables nurses to deal with difficult situations, manage crisis and thus solve problems. This consequently boosts their efficiency and enhances their adaptability to the environment, thus resulting in them being resilient. Kašpárkováa et al. (2018) stated that employees sense the availability of engagement as they have the ability to successfully control and influence their environment. Therefore, the first hypothesis, variance in work engagement scores can be statistically explained by individual emotional intelligence and resilience amongst nurses in public hospitals, is supported.

However, although an indirect link was observed, it is worth noting that the indirect effects of emotional intelligence were relatively smaller compared with the direct effects. A reasonable justification could be that the stronger direct relationship between emotional intelligence with resilience and work engagement decreased the amount of the variance of work engagement that could be accounted for by resilience. The findings are in line with Makikangas, Schaufeli, Tolvanen and Feldt (2013) who argued that the mediating effect of resilience is most effective when resilience as a personal resource mediates the relationship between job resources and work engagement. In this study, resilience, as a personal resource, mediated the relationship between personal resources and work engagement. Generally, these results suggest that emotional intelligence can directly influence the work engagement levels of nurses.

In essence, the findings from the model demonstrate that emotional intelligence, through regulating and managing one's emotions, fuels resilience, which then promotes higher levels of work engagement. Thus, the combined effect of emotional intelligence and resilience explains the 0.288 variance in work engagement. However, emotional intelligence had a stronger direct impact on work engagement. This suggests that emotional intelligence on its own can positively influence the work engagement levels of nursing employees. Thus, to boost nurses' work engagement levels, interventions should be focused more on emotional intelligence training. As the literature reviewed indicated that work engagement has benefits for both the organisation and the individual, focusing on emotional intelligence to ensure higher levels of work engagement is crucial for public hospitals.

The results indicated that resilience and emotional intelligence explained only $28.8 \%$ variance in work engagement, which can be interpreted as moderate contribution. With more organisations desiring to achieve high levels of work engagement at the moment, the impact of COVID-19 however has affected the work context, especially the nurses' working environment. In the context of the COVID-19 pandemic, it seems that nurses are overwhelmed with work and their engagement is both positively and negatively associated with health, well-being and work overload (Allande-Cussó et al., 2021). Studies indicated that although highly engaged employees may maintain high job performance, its positive effects on mental health seem to diminish after a certain level of engagement. Thus, the favourable effect of work engagement on mental health may reach an upper limit, after which it levels off, and adverse effects may occur especially when individuals are working under a lot of pressure, which is the case of nurses at the moment (Shimazu, Schaufeli, Kubota, Watanabe, \& Kawakami, 2018).

Although recent studies have shown that improving the level of work engagement of nurses increases their quality of work, job satisfaction and the sense of coherence and also their emotional well-being in the development of their profession, it is important to note that high levels of work engagement may result in promoting stress and work overload that characterises healthcare needs in the current COVID-19 conditions (Allande-Cussó et al., 2021). A recent study observed that most of the highly engaged nurses have suffered work overload, which has resulted in some of them quitting, especially professional nurses (Shimazu et al., 2018). 
Professional nurses tend to exhibit greater work engagement towards their work than most other nurses. However, their high levels of engagement maybe negatively influenced by busy schedules and work overload and maybe associated with burnout, mental exhaustion, work-life imbalance and conflict. Ideally, after administering interventions on improving work engagement, the managers need to teach coping skills for all the nurses during busy schedules, empowering them to achieve harmonious levels of engagement over a long and stressful work shift (Bushardt, Beal, Young, \& Khosl, 2016). Hospitals can provide assessment tools, counselling, training and other resources to assist in maintaining desired work engagement levels.

\section{Limitations of the study}

When interpreting the results from this study, the following limitations should be considered.

- The participants were made up of different categories of nurses (professional nurses, enrolled nurses, assistant nurses) exposed to different training and different job demands, which might have different influence on how they manage their emotions, acquire more personal resources and eventually become more engaged. The differences in the work context of these categories include the degree of autonomy, interaction with patients, working hours, role overload, lack of professional experience for some assistant nurses and closeness to recurring death situations may play a significant role in the interplay between the three variables under study. It is especially striking how nursing graduates (professional nurses ) along with nurses who have achieved an advanced diploma (enrolled nurses) may find it less difficult to bounce back, manage their emotions and eventually offer the highest work engagement scores compared with the assistant nurses who do not have adequate training and autonomy to their work. Having an adequate sample from one category of nurses would provide more consistent findings.

- As the study involved only professional nurses, assistant and enrolled nurses, results should only be generalised specifically to these categories of nurses. Also, because of the possibility of sampling error and lack of representation as the study used convenience sampling results were generalised to nurses who participated in the study and those with the same characteristics as them.

- Some of the categories of nurses investigated have limited scope of practice (assistant nurses), perform elementary and basic tasks and they work under instruction from the professional nurse, this influences their resilience and emotional intelligence because full responsibility for patient care lies with the professional nurse. Thus, it might be difficult to engage nurses whose duties are delegated by others.

- The study relied on a cross-sectional survey design, making it difficult to prove causal relationships between the variables.
- The study used self-administered questionnaires. Selfreported questionnaires could affect the trustworthiness and rigour (validity and reliability) of the findings as they can lead to response biases, such as social desirability bias. The use of paper-based copies of the questionnaire may give rise to impression management, which can be seen as a weakness of self-administered questionnaires.

- The questionnaire was only provided in English. Some of the Afrikaans and Sesotho-speaking nurses found some of the items difficult to understand, especially words such as 'immersed' and 'determined' in the UWES and resilience (RES).

Despite these limitations, the results of this study may be useful in an analysis of the relationship between emotional intelligence, resilience and engagement of employees in the public hospitals.

\section{Practical implications and recommendations}

The findings inform leaders and human resource practitioners of the dynamics between emotional intelligence, resilience and work engagement and help them design more effective employee-work engagement strategies. Considering that COVID-19 may affect nurses emotionally, assessing the way the nurses manage their emotions as a coping skill may shine a light on the initiatives designed to assist frontline workers during a pandemic. The results reveal that human resource practitioners need to consider the relationship between emotional intelligence, resilience and work engagement but mainly that between work engagement and emotional intelligence. The study observed that individuals with highly emotionally intelligent and resilient experience high levels of work engagement. However, a very strong link was observed between emotional intelligence and work engagement. In the light of these findings, organisations should try to develop organisational work environments that promote emotional intelligence, thereby boosting work engagement. Interventions aimed at raising awareness regarding these constructs and how to foster greater emotional intelligence and work engagement would lead to positive organisational outcomes.

\section{Future studies}

The study demonstrated that further research into the relationship between emotional intelligence, resilience and work engagement is necessary especially with homogenous groups of nurses. The study was conducted amongst 252 nurses, predominantly women, from three selected public hospitals in the Mangaung Metropolitan Municipality, South Africa. Future research should use a randomised sampling process with larger samples and include more male nurses. Future research should also employ a longitudinal design in order to gain insight into the constructs that influence work engagement. Future studies should focus on studying the mediating effects of other positive psychology variables. 


\section{Conclusion}

The main aim of this study was to determine the influence of emotional intelligence and resilience on work engagement and to determine the levels of work engagement, resilience and emotional intelligence of the nurses. The empirical statistical effect of emotional intelligence and resilience on work engagement observed in the study provided new understanding with respect to the engagement of employees. It also contributed to the development of a model for the facilitation of work engagement. This study concludes that both emotional intelligence and resilience play important roles in explaining employees' vigour, absorption and dedication in the workplace. However, the strong direct link between emotional intelligence and the dependent variable work engagement is very interesting. This strongly suggests that emotional intelligence should be the main focus in the promotion of work engagement in the workplace.

\section{Acknowledgements Competing interests}

The authors declare that they have no financial or personal relationships that may have inappropriately influenced them in writing this article.

\section{Authors' contributions}

P.C. developed the research idea and designed the study and was responsible for literature review, collected and analysed the data then compiled the manuscript. M.H. supervised the research done by P.C., reviewed the data analysed and was responsible for final integration of the research findings and assisted in compiling and proofreading the compiled manuscript.

\section{Funding information}

This research received no specific grant from any funding agency in the public, commercial, or not-for-profit sectors.

\section{Data availability}

Data can be made available by the first author, P.C. (chikopardonjd@gmail.com), upon reasonable request.

\section{Disclaimer}

The views and opinions expressed in this article are those of the authors and do not necessarily reflect the official policy or position of any affiliated agency of the authors, and the publisher/s.

\section{References}

Aiena, B., Baczwaski, B.J., Schulenberg, S., \& Buchanan, E. (2014). Measuring resilience with the RS-14: A tale of two samples. Journal of Personality Assessment, 97(3), 1-10. https://doi.org/10.1080/00223891.2014.951445

Albrecht, S.L. (2010). Handbook of employee engagement: Perspectives, issues, research and practice. Cheltenham: Edward Elgar Publishing Limited.
Allande-Cussó, R., García-Iglesias, J.J., Ruiz-Frutos, C., Domínguez-Salas, S., RodríguezDomínguez, C., \& Gómez-Salgado, J. (2021). Work engagement in nurses during the covid-19 pandemic: A cross-sectional study. Healthcare, 9(3), 253.

Bailey, C., Madden, A., Alfes, K., Fletcher, L., Robinson, D., Holme, J. ... Currie, G. (2015). Evaluating the evidence on employee engagement and its potential benefits to NHS staff: A narrative synthesis of the literature. Health Services and Delivery Research, 3, 26. https://doi.org/10.3310/hsdr03260

Bakker, A.B., \& Demerout, I.E. (2014). Job demands-resources theory. In P.Y. Chen \& C.L. Cooper (Eds.), Wellbeing: A complete reference guide, work and wellbeing (vol. 3, pp. 37-64). Hoboken, NJ: Wiley-Blackwell.

Bakker, A.B., \& Leiter, P.M. (Eds.). (2010). Work engagement: A handbook of essential theory and research. New York, NY: Psychology Press.

Banhwa, P.F., Chipunza, C., \& Chamisa, S.F. (2014). The influence of organisational employee engagement strategies on organisational citizenship behaviour within retail banking. A case of Amatole district municipality. Mediterranean Journal of Social Sciences, 5(6), 53. https://doi.org/10.5901/mjss.2014.v5n6p53

Bartlett, S. (2015). The relationship between emotional intelligence, work engagement, creativity and demographic variables. Unpublished Master's thesis. Pretoria: University of South Africa.

Bhootrani, M.L., \& Junejo, J. (2016). Emotional intelligence is a key to success. Journal of Liaquat University Medical \& Health Sciences, 15(3), 108-109.

Bjarnadotti, A. (2011). Work engagement among nurses in relationally demanding jobs in the hospital sector. Nursing Science, 31(3), 30-34. https://doi org/10.1177/010740831103100307

Boafo, I.M. (2018). The effects of workplace respect and violence on nurses' job satisfaction in Ghana: A cross-sectional survey. Human Resources for Health, 16(6), 60-69. https://doi.org/10.1186/s12960-018-0269-9

Bonner, L. (2016). A survey of work engagement and psychological capital levels. British Journal of Nursing, 25(15), 865-871. https://doi.org/10.12968/ bjon.2016.25.15.865

Brennan, E.J. (2017). Towards resilience and wellbeing in nurses. British Journal of Nursing, 26(1), 43-47. https://doi.org/10.12968/bjon.2017.26.1.43

Bushardt, S.C., Beal, B.D., Young, M., \& Khosla, S. (2016). Professional nurses and the dark side of work passion. Nursing Management, 47(1), 48-52. https://doi. org/10.1097/01.NUMA.0000475628.60011.eb

Damásio, B.F., Borsa, J.C., \& Da Silva, J.P. (2011). 14-item resilience scale (RS-14): Psychometric properties of the Brazilian version. Journal of Nursing Measurement 19(3), 131-145. https://doi.org/10.1891/1061-3749.19.3.131

Demerouti, E., \& Bakker, A.B. (2011). The job demands-resources model: Challenges for future research. SA Journal of Industrial Psychology, 37(2), a974. https://doi. org/10.4102/sajip.v37i2.974

Dewing, J., \& McCormack, B. (2015). Engagement: A critique of the concept and its application to person-centred care. International Practice Development Journal, 5, 6. https://doi.org/10.19043/ipdj.5SP.008

Extremera, N., Mérida-López, S., Sánchez-Álvarez, N., \& Quintana-Orts, C. (2018). How does emotional intelligence make one feel better at work? The mediational role of work engagement. International Journal of Environmental Research and Public Health, 15(9), 1909. https://doi.org/10.3390/ijerph15091909

Freeney, Y., \& Fellenz, M.R. (2013). Work engagement, job design and the role of the social context at work: Exploring antecedents from a relational perspective. HumanRelations, 66(11),1427-1445.https://doi.org/10.1177/0018726713478245

Garrosa, E., Moreno-Jiménez, B., Rodríguez-Muñoz, A., \& Rodríguez-Carvajal, R. (2011). Role stress and personal resources in nursing: A cross-sectional study of burnout and engagement. International Journal of Nursing Studies, 48(4), 479489. https://doi.org/10.1016/j.ijnurstu.2010.08.004

Geldenhuys, M., Łaba, K., \& Venter, C.M. (2014). Meaningful work, work engagement and organisational commitment. South African Journal of Industrial Psychology, 40(1), a1098. https://doi.org/10.4102/sajip.v40i1.1098

Giménez-Espert, M.C., Prado-Gascó, V., \& Soto-Rubio, A. (2020). Psychosocial risks, work engagement, and job satisfaction of nurses during COVID-19 pandemic. Frontiers in Public Health, 8, 1-10. https://doi.org/10.3389/fpubh.2020.566896

Goleman, D. (1995). Emotional intelligence. New York, NY: Bantam.

Hair, J.F., Risher, J.J., Sarstedt, M., \& Ringle, C.M. (2019). When to use and how to report the results of PLS-SEM. European Business Review, 31(1), 1-24. https://doi. org/10.1108/EBR-11-2018-0203

Hart, P.L., Brannan, J.D., \& Chesnay, M.D. (2014). Resilience in nurses: An integrative review. Journal of Nursing Management, 22(6), 720-734. https://doi. org/10.1111/j.1365-2834.2012.01485.x

Jacobs, S., Renard, M., \& Snelgar, R.J. (2014). Intrinsic rewards and work engagement in the South African retail industry. South African Journal of Industrial Psychology, 40(2), 1-13. https://doi.org/10.4102/sajip.v40i2.1195

Janse van Rensburg, A.P., Engelbrecht, M.C., Yassi, A., Nophale, L.E., Bryce, E.A., \& Spiegel, J.M. (2016). Selected features of nurses' occupational health and safety
practice in three Free State provincial public hospitals. Occupational Health practice in three Free State
Southern Africa, 22(2), 8-14.

Kašpárkováa, L., Vaculíka, M., Prochazka, J., \& Schaufel, W.B. (2018). Why resilient workers perform better: The roles of job satisfaction and work engagement. Journal of Workplace Behavioural Health, 33(1), 43-62. https://doi.org/10.1080/ 15555240.2018 .1441719

Kennedy, M., \& Julie, H. (2013). Nurses' experiences of workplace violence in a trauma and emergency department in South Africa. Health SA Gesondheid, 18(1), a663. https://doi.org/10.4102/hsag.v18i1.663 
Khamisa, N., Peltzer, K., llic, D., \& Oldenburg, B. (2015). Work related stress, burnout, job satisfaction and general health of nurses. International Journal of Environmental Research and Public Health, 12(1), 652-666. https://doi. org/10.3390/ijerph120100652

Kline, R.B. (2011). Principles and practice of structural equation modeling. New York, NY: The Guilford Press.

Koen, M.P., Van Eeden, C., \& Wissing, M.P. (2011). The prevalence of resilience in a group of professional nurses. Health SA Gesondheid, 16(1), a576. https://doi. org/10.4102/hsag.v16i1.576

Lestari, S.D., \& Sawitri, D.R. (2017). Correlation between emotional intelligence and work engagement of special need school teachers. Advanced Science Letters, 23(4), 3480-3482. https://doi.org/10.1166/asl.2017.9139

Llorens, S., Schaufeli, W., Bakker, A., \& Salanova, M. (2007). Does a positive gain spiral of resources, efficacy beliefs and engagement exist?. Computers in Human Behaviour, 23(1), 825-841. https://doi.org/10.1016/j.chb.2004.11.012

Magnano, P., Craparo, G., \& Paolillo, A. (2016). Resilience and emotional intelligence: Which role in achievement motivation. International Journal of Psychology Research, 9(1), 9-20. https://doi.org/10.21500/20112084.2096

Makikangas, A., Schaufeli, B., Tolvanen, A., \& Feldt, T. (2013). Engaged managers are not workaholics: Evidence from longitudinal person centred analysis. European Journal of Work and Organizational Psychology, 29(3), 135-143. https://doi. org/10.5093/tr2013a19

Maphumulo, W.T., \& Bhengu, B.R. (2018). Challenges of quality improvement in the healthcare of South Africa post-apartheid: A critical review. Curationis, 42(1), 1-9. https://doi.org/10.4102/curationis.v42i1.1901

Meintjes, A., \& Hofmeyr, K. (2018). The impact of resilience and perceived organisational support on employee engagement in a competitive sales environment. South African Journal of Human Resource Management, 16(11) 1-11. https://doi.org/10.4102/sajhrm.v16i0.953

Naidoo, V., Abarantyne, I., \& Rugimbana, R. (2019). The impact of psychological contracts on employee engagement at a university of technology. SA Journal of Human Resource Management, 17, a1039. https://doi.org/10.4102/sajhrm.v17i0.1039

Nel, P., Du Plessis, M., \& Bosman, L. (2015). Comparing different versions of the Rahim El questionnaire in a South African context: A confirmatory factor analysis approach. South African Journal of Industrial Psychology, 41(1), 9. https://doi. org/10.4102/sajip.v41i1.1220

Othman, N., \& Nasurdin, A.M. (2011). Work engagement of Malaysian nurses: Exploring the impact of hope and resilience. International Journal of Economics and Management Engineering, 5(12), 1990-1994.

Pérez-Fuentes, M., Molero Jurado, M., Gázquez Linares, J., \& Oropesa Ruiz, N. (2018) The role of emotional intelligence in engagement in nurses. International Journal of Environmental Research and Public Health, 15, 1915.

Prins, A., Van Niekerk, E., \& Weyers, A. (2018). Emotional intelligence: Tipping point in workplace excellence. Randburg: KR Publishing.

Rahim, M.A., Psenicka, C., Polychroniou, P., Zhao, J.-H., Yu, C.-S., Chan, K.A., ... Van Wyk, R. (2002). A model of emotional intelligence and confict management strategies: A study in seven countries. International Journal of Organizational Analysis, 10(4), 302-326. https://doi.org/10.1108/eb028955

Rispel, L.C. (2015). Transforming nursing policy, practice and management in South Africa. Global Health Action, 8, 28005. https://doi.org/10.3402/gha.v8.28005
Schaufeli, W.B., \& Bakker, A.B. (2004). UWES Utretcht work engagement scale: Preliminary manual (measuring instrument). Utrecht: Utrecht University, Occupational Health Psychology Unit.

Schaufeli, W.B., Salanova, M., González-Romá, V., \& Bakker, A.B. (2002). The measurement of engagement and burnout: A two-sample confirmatory factor analytic approach. Journal of Happiness Studies, 3, 71-93. https://doi. org/10.1023/A:1015630930326

Schneider, T.R., Lyons, J.B., \& Khazan, S. (2013). Emotional intelligence and resilience. Personality and Individual Differences, 55(8), 909-914. https://doi.org/10.1016/j. paid.2013.07.460

Shimazu, A., Schaufeli, W.B., Kubota, K., Watanabe, K., \& Kawakami, N. (2018). Is too much work engagement detrimental? Linear or curvilinear effects on mental health and job performance. PLoS One, 13(12), e0208684. https://doi. org/10.1371/journal.pone.0208684

Shuck, B., \& Herd, A.M. (2012). Employee engagement and leadership: Exploring the convergence of two frameworks and implications for leadership development in HRD. Human Resource Development Review, 11(2), 156-181.

Simons, J.C., \& Buitendach, J.H. (2013). Psychological capital, work engagement and organisational commitment amongst call centre employees in South Africa. South African Journal of Industrial Psychology, 39(2), 12. https://doi.org/10.4102/sajip. v39i2.1071

Sweetman, D., \& Luthans, F. (2010). The power of positive psychology: Psychological capital and work engagement. In A.B. Bakker \& M.P. Leiter (Ed.), Work engagement: $A$ handbook of essential theory and research (pp. 54-68). London: Psychology Press.

Takawira, N., Coetzee, M., \& Schreuder, D. (2014). Job embeddedness, work engagement and turnover intention of staff in a higher education institution: An exploratory study. South African Journal of Human Resource Management, 12(1), 524. https://doi.org/10.4102/sajhrm.v12i1.524

Terblanche, L., \& Borcherds, M. (2018). Managing workplace violence in a public hospital: A South African case study. Journal of Workplace Behavioural Health 33(2), 116-134. https://doi.org/10.1080/15555240.2018.1464931

Toyama, H., \& Mauno, S. (2017). Associations of trait emotional intelligence with social support, work engagement, and creativity in Japanese elder care nurses. Japanese Psychological Research, 59(1), 14-25. https://doi.org/10.1111/ jpr.12139

Van der Walt, F. (2018). Workplace spirituality, work engagement and thriving at work. SA Journal of Industrial Psychology, 44(1), 1-10. https://doi.org/10.4102/sajip. v44i0.1457

Wagnild, G.M., \& Collins, J. (2009). Assessing resilience. Journal of Psychosocial Nursing, 47(12), 28-33. https://doi.org/10.3928/02793695-20091103-01

Wagnild, G.M., \& Young, H.M. (1993). Development and psychometric evaluation of the resilience scale. Journal of Nursing Management, 1(2), 165-178.

Xanthopulou, D., Bakker, A.B., Demerouti, E., \& Schaufeli, W.B. (2007). The role of personal resources in the job demands-resources model. International Journal of Stress Management, 14(2), 121-141. https://doi.org/10.1037/1072 5245.14.2.121

Zhu, Y., Liu, C., Guo, B., Zhao, L., \& Lou, F. (2015). The impact of emotional intelligence on work engagement of registered nurses: The mediating role of organisational justice. Journal of Clinical Nursing, 24(15-16), 2115-2124. https://doi. org/10.1111/jocn.12807 